\title{
A Novel Passive Islanding Detection Scheme for Distributed Generations Based on Rate of Change of Positive Sequence Component of Voltage and Current
}

\author{
${ }^{1}$ Ali Rostami, ${ }^{2}$ Amin Jalilian, ${ }^{3}$ Seyed Behzad Naderi, ${ }^{3}$ Michael Negnevitsky, ${ }^{4}$ Pooya Davari and ${ }^{4}$ Frede Blaabjerg \\ ${ }^{I}$ Department of Electrical Engineering, South Tehran Branch, Islamic Azad University, Tehran, Iran \\ ${ }^{2}$ Young Researchers and Edit Club, Kermanshah Branch, Islamic Azad University, Kermanshah, Iran \\ ${ }^{3}$ School of Engineering and ICT, University of Tasmania, Hobart, TAS, 7001, Australia \\ ${ }^{4}$ Department of Energy Technology, Aalborg University, Aalborg, Denmark
}

\begin{abstract}
Islanding operation is one of serious hazards of distributed generation (DG) applications. According to IEEE 1547 standard, its occurrence must be detected within two seconds. This paper presents a novel passive islanding detection method based on rate of change of positive sequence component of voltage (RCPSV) and rate of change of positive sequence component of current (RCPSC) acquired at point of common coupling (PCC) of the targeted DG. Whenever the RCPSC and RCPSV are not equal to zero, their change of magnitudes is continuously compared to predetermined threshold values. If both values of RCPSC and RCPSV exceed the predetermined threshold values, it is concluded that the islanding condition has occurred. Otherwise, it is considered as a non-islanding event. The performance of the proposed method is investigated on a sample network in the presence of doubly fed induction generator (DFIG) based wind turbine and synchronous diesel generator DGs by MATLAB/Simulink software. Different nonislanding case studies are taken into account to evaluate the effectiveness of the proposed approach. The simulation results show that the proposed method has advantage of detecting the islanding rapidly and accurately even with zero non-detection zone (NDZ).
\end{abstract}

Keywords-passive method, islanding detection, positive sequence, voltage and current

\section{INTRODUCTION}

The presence of distributed generations (DGs) into the power systems, along their advantages, have some disadvantages such as increased short circuit level, reduced power quality, unitentional islanding, etc. The unitentional islanding is one of the serious hazards of DGs' application. When the islanding occurs, the power system loads are only energized by the DG units while the main grid is detached. Islanding operation has some technical problems and hazards such as line worker safety, reduced power quality, failure protection and so forth. According to the mentioned hazards of the islanding operation, IEEE 1547 standard emphasizes that, it is very serious to detect the islanding status and isolate the DG units from the main network within two seconds [1-2]. Islanding detection methods, which have been introduced by researchers, include two groups of remote and local methods. The remote methods operate based on a communication between the DG units and the main network. These methods are not affected by power mismatch conditions; However, their application is quite uneconomical. Local methods include three groups of passive, active, and hybrid methods [2].
In passive methods, the islanding is detected by measuring the magnitude change of different electrical parameters at the DG connection point and then their maximum change value are compared to the predetermined threshold values. These methods do not have any negative impact on normal condition of the power system. However, they have non-detectable zone for power match of active and reactive powers. Some of these methods include: frequency relay, voltage relay, rate of change of frequency (ROCOF) relay, rate of change of phase angle difference (ROCPAD) relay, rate of change of impedance, rate of change of sequence components of current, single-phase operating circuit breaker, inverse hyperbolic secant function, system identification, rate of change of frequency over reactive power, voltage phase angle, feature extractions from differential transient rate of change of frequency, and use of multi features to reduce non-detection zone (NDZ) of vector surge relay, rate of change of negative sequence voltage and current [3-16].

In active methods, the islanding can be detected by the power systems reaction to the intentional applied disturbances. Thus, by comparing the magnitude change of various electrical parameters with the predetermined threshold values, the islanding can be detected. The active methods are more effective than the passive methods, but, they reduce the power quality. Some of these methods includes: high-frequency signal injection, reactive power control, negative-sequence current injection, active ROCOF relay, and second harmonic drifting, active current disturbance [17-22].

According to the disadvantages of the each mentioned methods, both could not be solely effective. So, recently, the hybrid methods, which consist of combination of the passive and the active methods, are introduced. Some of these methods includes: average rate of voltage change and real power shift, rate of change of reactive power and load connection strategy, the ROCOV and ROCORP with capacitor connection, and load shedding method [23-26].

This paper presents a new hybrid passive islanding detection method based on rate of change of positive sequence of voltage (RCPSV) and rate of change of positive sequence of current (RCPSC) signals, which are acquired at the point of 
common coupling (PCC) of the targeted DG. All conditions can be detected by comparing the RCPSV and RCPSC parameters with their threshold values. In fact, if both values of the RCPSC and the RCPSV exceed the predetermined threshold values, it can be concluded that the islanding operation has occurred. Otherwise, it is considered as the nonislanding event. The proposed method can rapidly and accurately detect the islanding condition even with zero NDZ value.

The rest of this paper is organized as follows. Part II includes the proposed methodology. Part III describes the case study system. Part IV presents the simulation results. In Part $\mathrm{V}$, a conclusion of this paper is given.

\section{THE PROPOSED METHOdOLOGY}

\section{A. Flowchart of the Proposed Method}

According to Fig. 1, which shows schematic diagram of detection process, the current and the voltage are measured at the PCC. Then, phasor quantities of the current and the voltage are converted into the positive sequence components. So, the rate of change of positive sequence of voltage (RCPSV) and the rate of change of positive sequence of current (RCPSC) are calculated. When the RCPSC $\neq 0$ and RCPSV $\neq 0$ are detected, the values of RCPSC and RCPSV are continuously compared to the predetermined threshold values of $\mathrm{set}_{1}$ and $\mathrm{set}_{2}$, respectively. If both values of RCPSC and RCPSV are more than the predetermined threshold values, it is concluded that the islanding has occurred. Otherwise, if each sample value of the RCPSC or the RCPSV becomes less than the predetermined threshold values, it is considered as the non-islanding condition. Both threshold values of set $_{1}$ and set 2 are adjusted to $0.2 \mathrm{p} . \mathrm{u} / \mathrm{sec}$. Flowchart of the proposed method is presented in Fig. 2.

\section{B. Mthematical Principle of the Proposed Method}

Positive sequence components are given by (1) and (2).

$$
\begin{gathered}
I_{+}=1 / 3 \times\left(I a+a I_{b}+a^{2} I_{c}\right) \\
V_{+}=1 / 3 \times\left(V a+a V_{b}+a^{2} V_{c}\right)
\end{gathered}
$$

where $I_{a}, I_{b}$ and $I_{c}$ are currents of phases $a, b$ and $c$, respectively. Also, $V_{a}, V_{b}$ and $V_{c}$ are voltages of phases $a, b$ and $c$, respectively. The complex operator is $a=1 \angle 120^{\circ}$.

At the PCC, the voltage is ' $V_{P C C}$ ' before the islanding occurrence. However, after the islanding, the voltage at the PCC changes to ' $V_{P C C}(1+\Delta V)$ '. According to Fig. 1, before the islanding, the load current is given by (3).

$$
I_{L}=\frac{V_{P C C}}{Z_{L}}
$$

where $Z_{L}$ is the value of load impedance.
After the islanding detection, the load current is expressed by (4).

$$
I_{L}{ }^{\prime}=V_{P C C}(1+\Delta V) / Z_{L}
$$

As a result, after the islanding, the phase currents $I_{a}, I_{b}$ and $I_{c}$ change to $I_{a}+\Delta I_{a}, I_{b}+\Delta I_{b}$ and $I_{c}+\Delta I_{c}$, respectively. Also, the phase voltages $V_{a}, V_{b}$ and $V_{c}$ change to $V_{a}+\Delta V_{a}$, $V_{b}+\Delta V_{b}$ and $V_{c}+\Delta V_{c}$, respectively. Therefore, the values of positive sequence of voltage and current after the islanding occurrence are expressed in (5) and (6).

$$
\begin{gathered}
I_{+}^{\prime}=1 / 3 \times\left\{\left(I_{a}+\Delta I_{a}\right)+a\left(I_{b}+\Delta I_{b}\right)+a^{2}\left(I_{c}+\Delta I_{c}\right)\right\} \\
V_{+}^{\prime}=1 / 3 \times\left\{\left(V_{a}+\Delta V_{a}\right)+a\left(V_{b}+\Delta V_{b}\right)+a^{2}\left(V_{c}+\Delta V_{c}\right)\right\}
\end{gathered}
$$

The value of $d v_{+} / d t$ and $d i_{+} / d t$ during the islanding condition are given in (7) and (8).

$$
\begin{aligned}
& \frac{d V_{+}}{d t}=\frac{\Delta V_{a}+a V_{b}+a^{2} \Delta V_{c}}{\Delta t} \\
& \frac{d I_{+}}{d t}=\frac{\Delta I_{a}+a I_{b}+a^{2} \Delta I_{c}}{\Delta t}
\end{aligned}
$$

According to (9) and (10), the RCPSV and RCPSC are the maxmimum sample of the positive sequence component of voltage and the positive sequence component of current, respectively.

$$
\begin{aligned}
& R C P S V=\max \left\{(R C P S V)_{1},(R C P S V)_{2}, \ldots,(R C P S V)_{n}\right\} \\
& R C P S C=\max \left\{(R C P S C)_{1},(R C P S C)_{2}, \ldots,(R C P S C)_{n}\right\}
\end{aligned}
$$

where $n$ is number of sampling during monitor time.

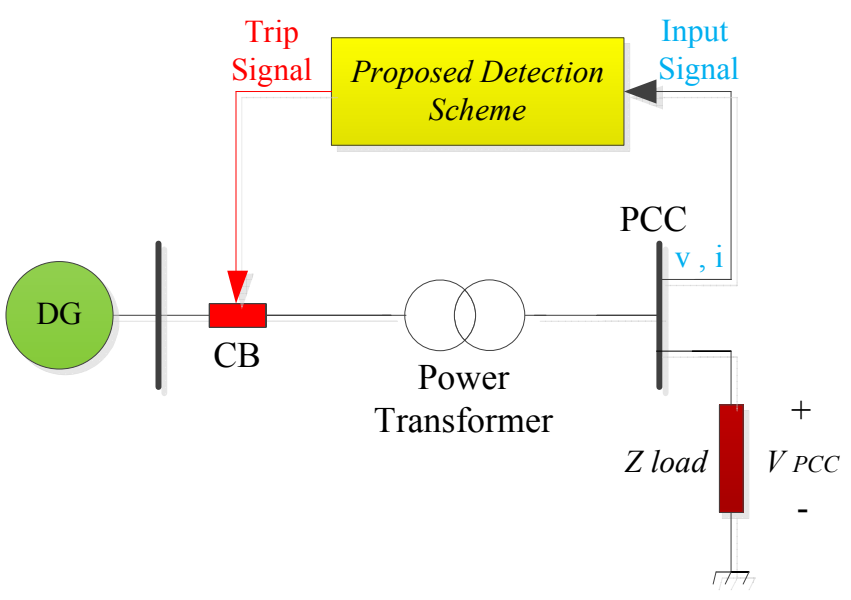

Fig. 1. Schematic diagram of detection process. 


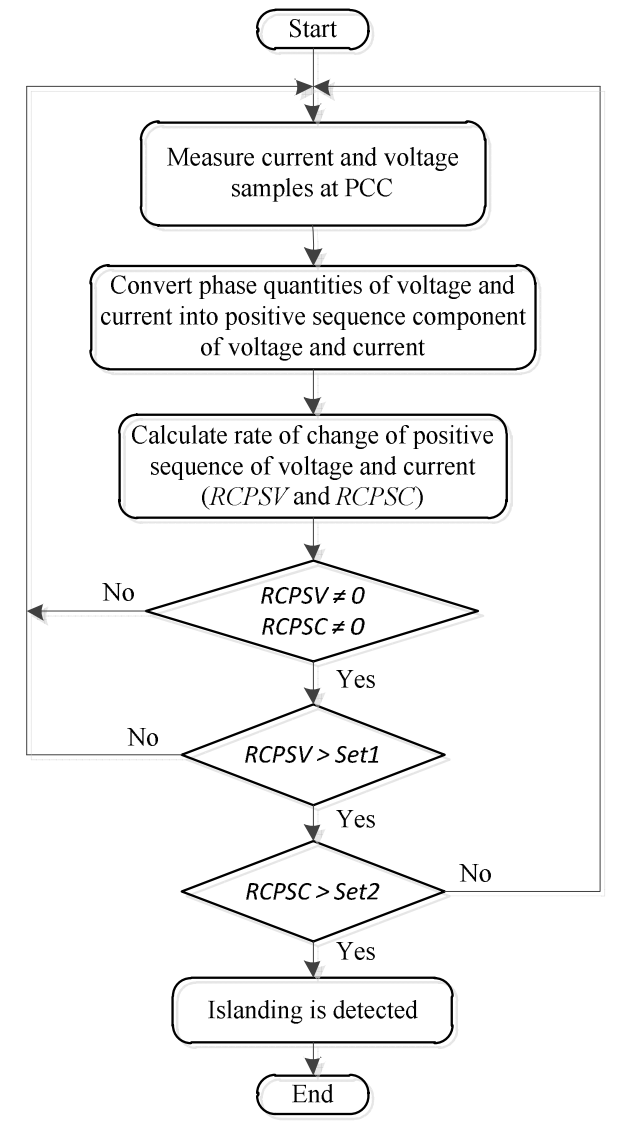

Fig. 2. Flowchart of the proposed method.

\section{CASE StUdy System}

The single line diagram of the case study system is shown in Fig. 3, and its parameters are presented in Table I.

TABLE I. SimUlated POWER SySTEM PARAMETERS

\begin{tabular}{|c|c|}
\hline \multirow{2}{*}{ DG } & $\begin{array}{l}1.5 \times 6 \mathrm{MW} \text { wind turbines } \\
9 \mathrm{MW}, 575 \mathrm{~V}, 60 \mathrm{~Hz}\end{array}$ \\
\hline & $\begin{array}{l}\text { Woodward governor model } \\
\text { IEEE AC1A-type exciter } \\
\text { 3.125MVA, 60Hz, 575V }\end{array}$ \\
\hline Transformers & $\begin{array}{c}R_{I}=R_{2}=0.0026 \text { p.u. } \\
L_{1}=L_{2}=0.08 \text { p.u., } R m=X m=500 \text { p.u. }\end{array}$ \\
\hline $\begin{array}{l}\text { Asynchronous } \\
\text { Motor }\end{array}$ & $\begin{array}{c}R_{s}=0.0092 \mathrm{p} . \mathrm{u}, L_{s}=0.0717 \text { p.u. } \\
R_{r}=0.007 \text { p.u, } L_{r}=0.0717, L_{m}=4.14 \text { p.u. }\end{array}$ \\
\hline
\end{tabular}

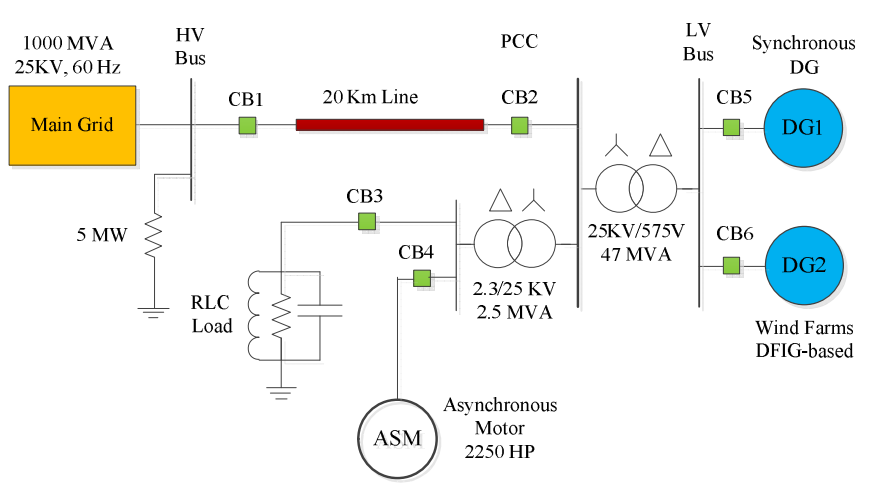

Fig. 3. The simulated power system.

\section{SIMULATION RESULTS}

\section{A. Islanding occurrence scenario}

The islanding detection method may be seriously affected by the NDZ of active and reactive powers. In fact, for the islanding occurrence with small power mismatch, the power system parameter changes are very small. Therefore, the detection method will not be probably able to detect the islanding condition. Therefore, to assess the effectiveness of the proposed method, various power mismatches of active and reactive powers from $0 \%$ to $70 \%$ are taken into account. The RCPSV and RCPSC variations for the islanding occurrence are shown in Fig. 4. As it is clear, for three cases of the islanding occurrence, $d v_{+} / d t$ and $d i_{+} / d t$ exceed set $_{1}$ and $\operatorname{set}_{2}$, respectively. Consequently, all these cases are accurately classified as the islanding events. The methods in [3-5] have false detection for the perfect power match condition, and the islanding condition is not detected. While, by the proposed method of this paper, the islanding occurrence is detected even for the perfect power match condition.

\section{B. Short-circuit fault occurrence scenario}

When a short circuit fault occurs, the islanding detection method may be affected. In this section, the proposed method is evaluated for various short circuit faults including singlephase, double-phase and three-phase faults. The RCPSV and RCPSC variations of the short-circuit fault conditions are shown in Fig. 5. It is shown that for three-phase and doublephase faults, $d v_{+} / d t$ is more than $s e t_{1}$ but $d i_{+} / d t$ for both fault conditions is less than set. However, for single phase fault, $d v_{+} / d t$ and $d i_{+} / d t$ are less than $\operatorname{set}_{1}$ and $s e t_{2}$, respectively. Therefore, all these tests are correctly detected as nonislanding events. The studied method in [7] has false detection for three-phase fault at the adjacent feeder. Then, the threephase fault cannot be distinguished from the islanding condition. While, in this paper, the proposed method accurately distinguishes all short-circuit faults from the islanding condition.
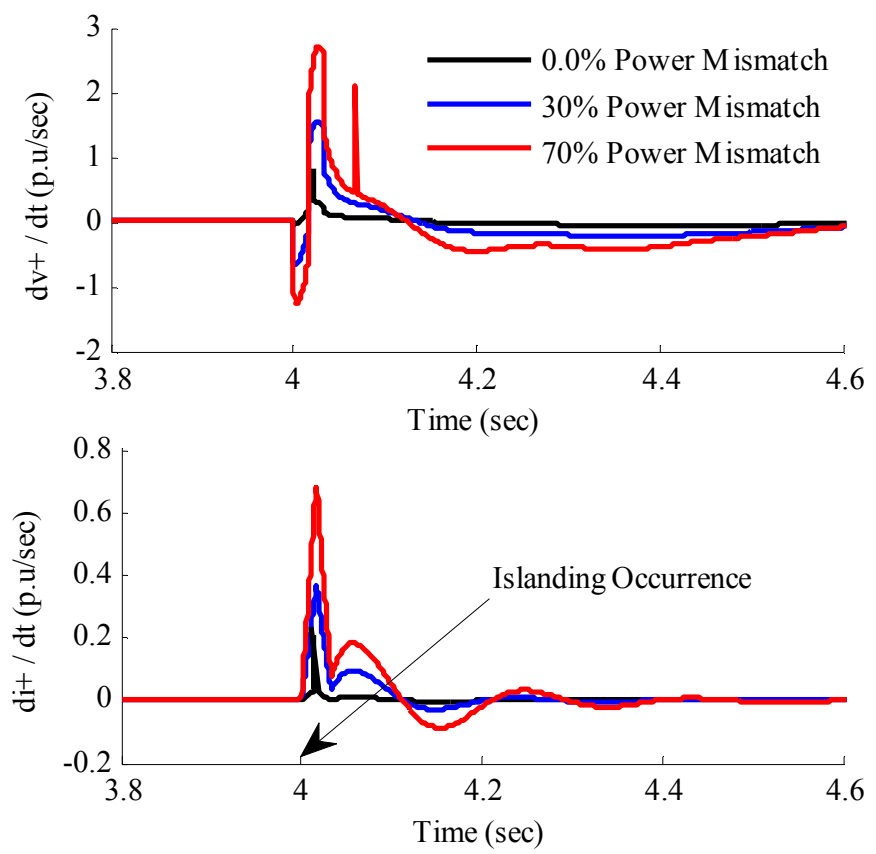

Fig. 4. Waveforms of $d v+/ d t$ and $d i_{+} / d t$ for the islanding occurrence with different power mismatches. 

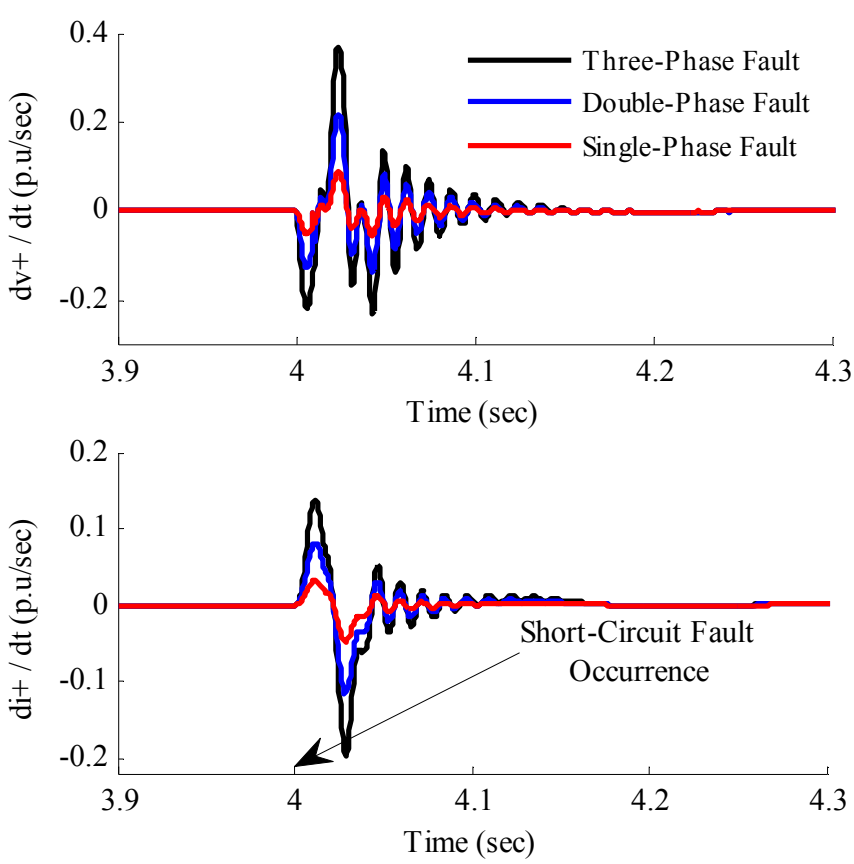

Fig. 5. Waveforms of $d v_{+} / d t$ and $d i_{+} / d t$ for different types of the short-circuit faults.

\section{Capacitor switching scenario}

Capacitors, which are connected in parallel to the power system, are commonly utilized for power factor correction, voltage sag compensation and etc. In instant of capacitor switching, the electrical parameters of the power system change, which may lead to the false detection. In this section, the proposed method is evaluated for capacitor switching with different capacities. The RCPSV and the RCPSC variations of switching events are shown in Fig. 6. It can be seen that for all these case studies, $d v_{+} / d t$ exceeds $s e t_{1}$, however $d i_{+} / d t$ is less than set $_{2}$. Therefore, all these cases are correctly detected.

\section{Motor switching scenario}

In instant of motor switching, both connecting/disconnecting states, the electrical parameters of the power system change, which may lead to interference in the DGs' anti-islanding protection. Therefore, in this section, the performance of proposed method is assessed for the induction motor switching. These tests show that how the proposed method distinguishes the induction motor switching events from the islanding occurrence. The RCPSV and the RCPSC variations during the induction motor switching are shown in Fig. 7. As it is obvious, for two power levels of the induction motor, $d v_{+} / d t$ is less than $s e t_{1}$ but $d i_{+} / d t$ for both states is more than set $t_{2}$. As a result, the wrong detection of $d i_{+} / d t$ is avoided by $d v_{+} / d t$. In fact, all these conditions are correctly detected as the non-islanding events.

The proposed method in [8] may lead to false detection for motor switching. While, the proposed method of this paper is correctly identified the induction motor switching.

\section{A. Load switching scenario}

One of disturbances, which some of the islanding detection methods probably operate wrong, are load switching conditions. In this section, the performance of the proposed method is taken into account for the load switching
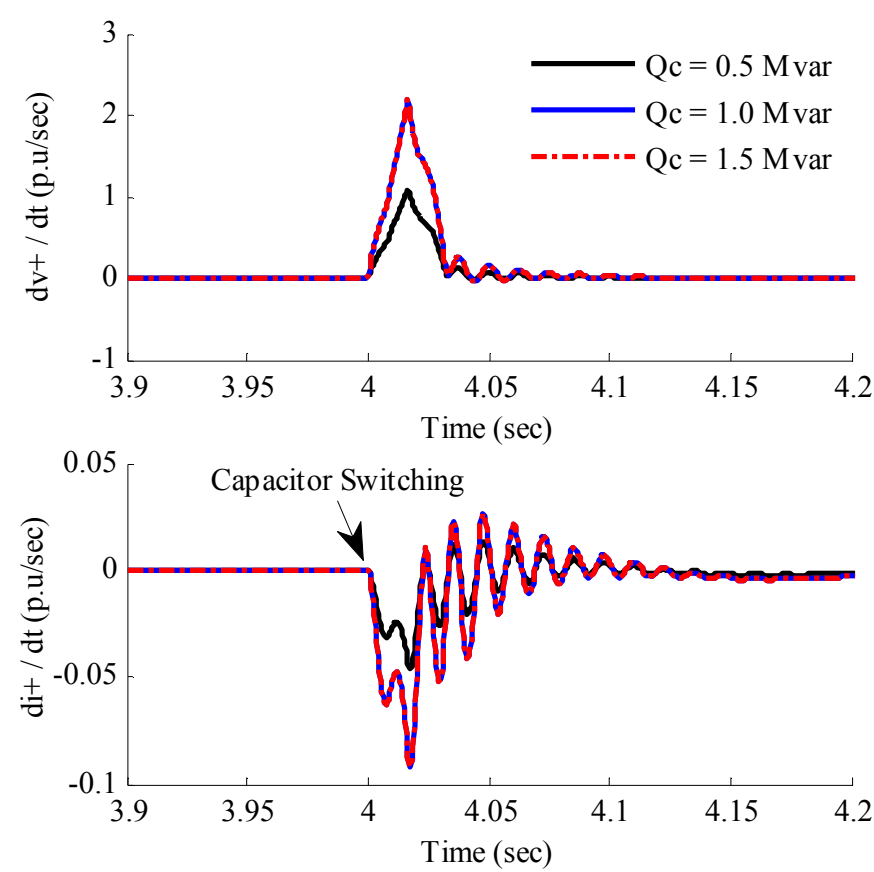

Fig. 6. Waveforms of $d v_{+} / d t$ and $d i_{+} / d t$ for three reactive power level of capacitors during switching.
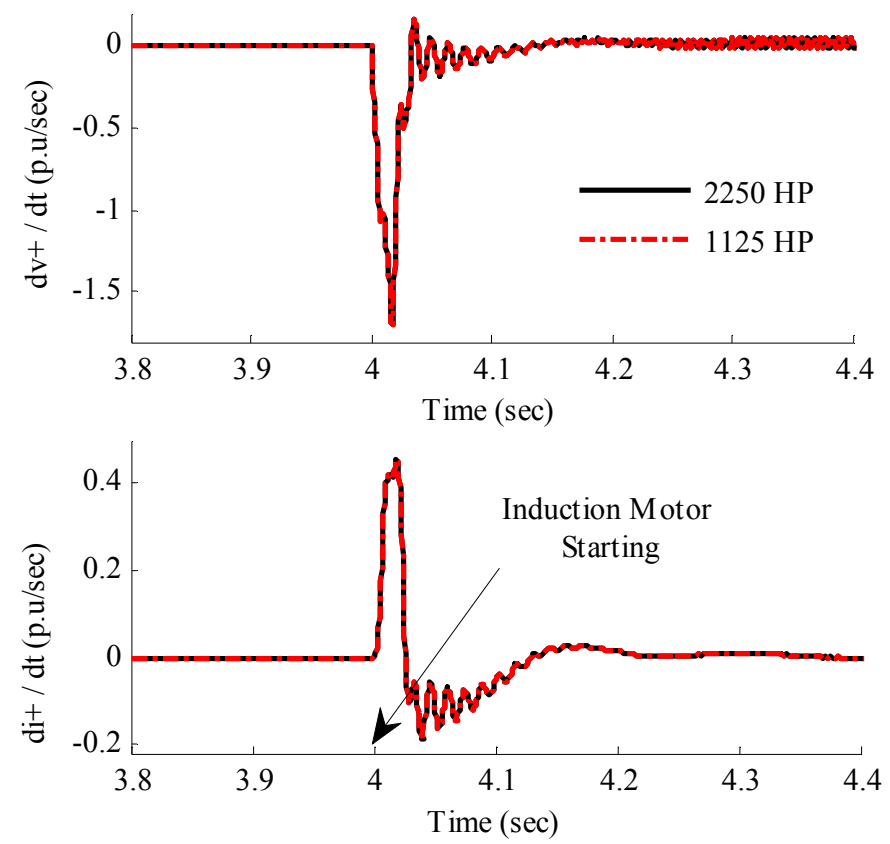

Fig. 7. Waveforms of $d v_{+} / d t$ and $d i_{+} / d t$ for two power level of the induction motor during starting.

with different power levels. These case studies prove that how the proposed method identifies the difference between the load switching events and the islanding condition. The RCPSV and the RCPSC variations of the switching events are shown in Fig. 8. It can be seen that for both cases of the load changing, $d v_{+} / d t$ and $d i_{+} / d t$ are less than $\mathrm{set}_{1}$ and $s e t_{2}$, respectively. Therefore, all load switching states are correctly classified as non-islanding events.

The proposed method in [24] has a high sensitivity even for nominal loading changes, which may lead to a false detection. While, the proposed approach of this paper is quite robust for the load changing. 

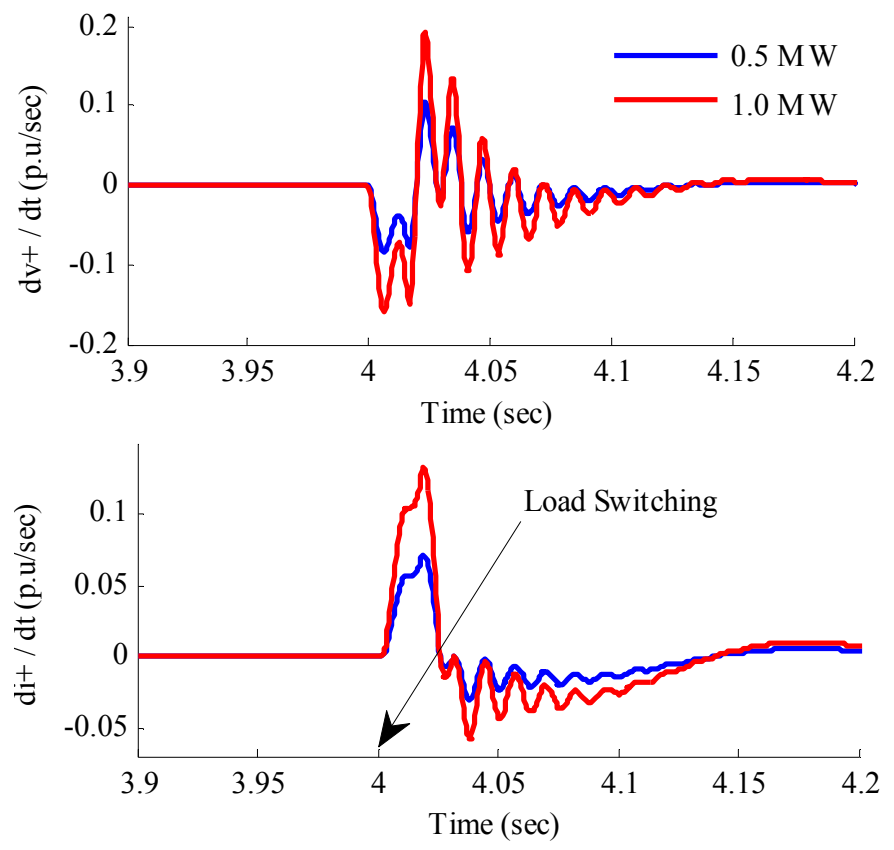

Fig. 8. Waveforms of $d v_{+} / d t$ and $d i_{+} / d t$ for two power levels during load switching.

\section{CONCLUSION}

This paper presents a new hybrid islanding detection method based on the rate of change of positive sequence of voltage (RCPSV) and the rate of change of positive sequence of current (RCPSC). The islanding conditions could be detected by comparing the RCPSV and the RCPSC with their predetermined threshold values. The performance of the proposed method is investigated on a sample network in the presence of doubly fed induction generator based wind turbine (DFIG) and synchronous diesel generator DGs. The simulation results prove that the proposed method can easily distinguish all the non-islanding events including short circuit fault condition, capacitor switching, induction motor switching and load switching from the islanding situation. Meanwhile, the proposed hybrid method is capable to rapidly and accurately detect the islanding condition even with zero NDZ. In fact, it completely eliminates the non-detection zone.

\section{REFERENCES}

[1]. IEEE 1547 Standard for Interconnecting Distributed Resources With Electric Power Systems, Std. 1547, 2003.

[2] D. Velasco, C. Trujillo, L. Garcera and G. Figueres, "Review of antiislanding techniques in distributed generators," Renewable and Sustainable Energy Reviews, vol. 14, no. 6, pp. 1608-1614, August 2010.

[3]. J-C-M. Vieira, W. Freitas, W. Xu and A. Morelato, "Performance of frequency relays for distributed generation applications," IEEE Trans. Power Del., vol. 21, no. 3, pp. 1120-1127, July 2006.

[4]. J-C-M. Vieira, W. Freitas and D. Salles, "Characteristics of voltage relays for embedded synchronous generators protection," IET Gener. Transm. and Distrib., vol. 1, no. 3, pp. 484-491, May 2007.

[5]. J-C-M. Vieira, W. Freitas, W. Xu and A. Morelato, "Efficient coordination of ROCOF and frequency relay for distributed generation protection by using the application region," IEEE Trans. Power Del, vol. 21, no. 4, pp. 1878-1884, October 2006.

[6]. A. Samui, and S-R. Samantaray, "Assessment of ROCPAD relay for islanding detection in distributed generation," IEEE Transactions on Smart Grid, vol. 2, no. 2, pp. 391-398, June 2011.

[7]. H-S. Pragnesh, and R-B Bhavesh, "A new rate of change of impedancebased islanding detection scheme in presence of distributed generation," Electric Power Components and Systems, vol. 42, no. 11, pp. 1172-1180, July 2014.
[8]. K. Sareen, B-R. Bhalja, R-P. Maheshwari "Universal islanding detection technique based on rate of change of sequence components of currents for distributed generations" IET Renew. Power Gener, vol. 5, no. 6, pp. 1-10, August 2015.

[9]. Y. Shang and S. Shi "Islanding detection method adopting single-phase operating circuit breaker" IET Gener. Transm. Distrib, vol. 10, no. 4, pp. 1039-1047, March 2016.

[10]. K. Sareen, B-R. Bhalja, R-P. Maheshwari "Islanding detection technique based on inverse hyperbolic secant function" IET Renew. Power. Gener, vol. 10, no. 7, pp. 1002-1009, July 2016.

[11]. L. Shihan, L. Yanjung, J. Xiang, J. Feifan "Islanding detection method based on system identification" IET Power Electronics, vol. 9, no. 10, pp. 2095-2102, August 2016.

[12]. R. Safdar, H. Mokhlis, H. Arof, J-A. Laghari and H. Mohammad, “ A sensitivity analysis of different power system parameters on islanding detection "IEEE Transactions on Sustainable Energy, vol. 7, no. 2, pp. 461470, April 2016.

[13]. H. Pourbabak and A. Kazemi, "A new technique for islanding detection using voltage phase angle of inverter-based DGs," Electrical Power and Energy Systems, vol. 57, pp. 198-205, May 2014.

[14]. F. Hashemi, M. Mohammadi, A. Kargarian, “ Islanding detection method for micro grid based on extracted features from differential transient rate of change of frequency," IET Gener. Transm. Distrib, Vol. 11, no. 4, pp. 891-904, March 2017.

[15]. M-R. Alam, K-M. Muttaqi, S. Bouzerdoum, "A Multi feature-based approach for islanding detection of DG in the subcritical region of vector surge relays," IEEE Transactions on Power Delivery, vol. 29, no. 5, pp. 23492358, March 2014.

[16] K-M. Kumar, M. Naresh, N-K. Singh, A-K. Singh, "A passive islanding detection approach for distributed generation using rate of change of negative sequence voltage and current," IEEE Uttar Pradesh Section International Conference on Electrical, Computer and Electronics Engineering (UPCON), December 2016.

[17]. D. Reigosa, F. Briz, C. Blanco, P. Garc'ia and J-M Guerrero, “Active islanding detection for multiple parallel-connected inverter-based distributed generators using high-frequency signal injection," IEEE Transactions on Power Electronics, vol. 29, no. 3, pp. 1192-1199, March 2014.

[18]. X. Chen, and Y. Li, "An islanding detection algorithm for inverter-based distributed generation based on reactive power control," IEEE Transactions on Power Electronics, vol. 29, no. 9, pp. 4672-4683, September 2014.

[19]. H. Karimi, A. Yazdani and R. Iravani, "Negative-sequence current injection for fast islanding detection of a distributed resource unit," IEEE Transactions on Power Electronics, vol. 23, no. 3, pp. 298-307, January 2008.

[20]. P. Gupta, R-S. Bhatia, D-K. Jain, “ Active ROCOF relay for islanding detection," IEEE Transactions on Power Delivery, vol. 32, no. 1, pp. 420-429, Feb 2017.

[21]. A. Emadi, H. Afrakhte, J. Sadeh, "Fast active islanding detection method based on second harmonic drifting for inverter-based distributed generation," IET Gener, Transm. Distrib. Vol. 10, no. 14, pp. 3470-3480, October 2016.

[22] H. Ding, Y. Wei, X. Wang, J. Yuan, D. Zhang, J. Zhang, L. Xiangli, Q. Hanhong, "A novel islanding detection based on adaptive active current disturbance," IEEE Conference and Expo Transportation Electrification AsiaPacific, September 2014.

[23]. P. Mahat, Z. Chen and B-B. Jensen, "A hybrid islanding detection technique using average rate of voltage change and real power shift," IEEE Transactions on Power Delivery, Vol. 24, no. 2, pp. 764-771, April 2009.

[24]. J-A. Laghari, H. Mokhlis, A-H-A. Bakar and M. Karimi, "A new islanding detection technique for multiple mini hydro base on the rate of change of reactive power and load connecting strategy," Energy Conversion and Management, vol. 76, pp. 215-224, December 2013.

[25]. A. Rostami, H. Abdi, M. Moradi, J. Olamaei and E. Naderi, "Islanding detection based on ROCOV and ROCORP parameters in the presence of synchronous DG applying the capacitor connection strategy," Electric Power Components and Systems, vol. 45, no. 3, pp. 315-330, January 2017.

[26]. K. Narayanan, S-A. Siddiqul, M. Fozdar, "Hybrid islanding detection method and priority based load shedding for distribution networks in the presence of DG units," IET Gener. Transm. Distrib, vol. 11, no. 3, pp. 586595, February 2017. 